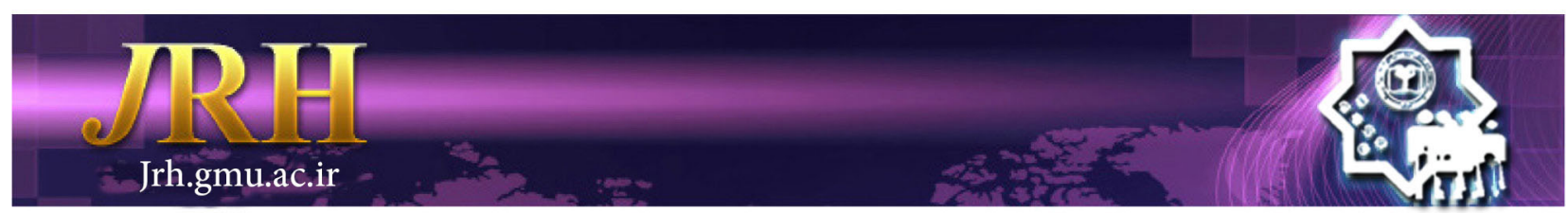

\title{
Effect of transactional analysis group therapy on couples' marital adjustment
}

Saeedeh Sedighi ${ }^{1}$, Shahrokh Makvand Hoseini ${ }^{2}$, Bahram Ali Qanbari

Hashem Abadi ${ }^{3}$, Ali Mohebi Anabat ${ }^{1}$, Mohammad Ebrahim Hokm

Abadi $^{4}$

\author{
Journal of Research \& Health \\ Social Development \& Health Promotion \\ Research Center \\ Vol. 8, No. 4, Jul \& Aug 2018 \\ Pages: $356-364$ \\ DOI: $10.29252 /$ jrh.8.4.356 \\ Original Article
}

\begin{abstract}
1. Department of Clinical Psychology, Faculty of Educational Sciences and Psycholog, Semnan University, Semnan, Iran

2. Department of Psychology, Faculty of Educational Sciences and Psycholog, Semnan University, Semnan, Iran

3. Department of Psychology, Faculty of Educational Sciences and Psycholog, Ferdowsi University of Mashhad, Mashhad, Iran

4. Department of Health Psychology, Faculty of Educational Sciences and Psycholog، Azad University of Gorgan, Gorgan, Iran

Correspondence to: Saeedeh Sedighi, Department of Clinical Psychology، Faculty of Educational Sciences and Psycholog, Semnan University, Semnan, Iran

Email: Sedighi_saeedeh@yahoo.com
\end{abstract}

Received: 24 Sep 2014

Accepted: 21 Jan 2015

How to cite this article: Sedighi S, Makvand Hoseini Sh, Qanbari Hashem Abadi BA, Mohebi Anabat A, Hokm Abadi ME. Effectiveness of transactional analysis group therapy on couples' marital adjustment. $J$ Research Health2018; 8(4): 356- 364

\begin{abstract}
Although all societies consider marriage as one of mental health factors, mental health cannot be realized if the marriage does not create adverse conditions to satisfy psychological needs of spouses. Therefore, this study aimed to evaluate effect of Transactional Analysis group therapy on couples' marital adjustment. This is a quasi-experimental study with control group, pretest-posttest design and 3 months follow-up test. The statistical population consisted of all the couples who attending at the counseling center in Mashhad. The sample included 16 couples who were selected by convenience sampling method and was assigned to experimental and control groups randomly. The experimental group received 8 sessions of Transactional Analysis group therapy. The instrument in this research was Dyadic Adjustment Scale. All couples completed Dyadic Adjustment Scale at pre-treatment and post-treatment and at 3 months followup. The data was analyzed by Repeated Measure Analysis of Variance. The results showed that scores of experimental group was significantly higher in affectional expression and total dyadic adjustment in posttest and the follow-up in comparison of control group. As a result, Transactional Analysis group therapy seems effective intervention method is increasing marital adjustment.
\end{abstract}

Keywords: Transactional Analysis, marital adjustment

\section{Introduction}

During the recent decade, while numerous studies have been conducted about marriage and effect of its factors on personal problems such as depression and drug abuse various research has focused on curing marital problems [1].

Researches have been shown that marital maladjustment can have extensive effects on people, in manner which may cause reduces physical and psychological health, decreasing of happiness and life satisfaction [2], as well as more depression [3] and lower self-esteem
[4]. So, emphasis on components of marital adjustment in couple therapy interventions can be quite effective.

Marital adjustment is situation in which husband and wife feel happy and satisfied from each other in the most cases [5]. The result of this process is based on couples' degree of consensus over important issues including sexual relationship, couples' persistent commitment to sexual relationship, couples' degree of participation in performing joint 
activities, and couples' emotional and physical intimacy [6]. Marital adjustment in couples with stronger communication skills is higher in comparison to those with weaker communication skills [7].

Among different psychological viewpoints, Transactional Analysis (TA) is outstanding in terms of theoretical depth and its vast and varied application. TA consultation is helpful relationship that qualified therapist employs TA methods to increase adult knowledge of the perspective of the problem solution in client or group. The TA method is adopted for making changes by means of proper techniques based on here and now. It aims to increase the patient's cognitive and emotional knowledge with respect to particular damaged area (problems concerned with relationships or performance) [8].

In the book "Principles of Group Treatment," Berne differentiated between four types of group therapy: supportive therapy, group analytic therapy, psychoanalytic therapy in group, and TA. Certainly TA is certainly unique method in using group for working with people's scenarios. In TA group therapy, analysis of transactions, games, and ego states which often takes place between patient and therapist in individual therapy sessions can be greatly useful by concentration and enhancing the initial relationships displayed by group members (as well as between group members and the therapist) [9].

Couples in therapy would experience higher intimacy by familiarity with various types of strokes and by increased unconditional positive strokes in their relationship, greater use of reciprocal transactions, and replacing the crossed transactions with the mentioned transactions as well as avoiding ulterior transactions. The couples become familiar with psychological games in the sessions and learn how to abandon and deal with them. The therapy process aims to get the couples to the final status of "I'm okay and you're okay." By reinforcing the "adult" of each person and teaching problem solving based on here and now as well as concluding growth contract, this method paves the way for increasing marital adjustment and consequently, increasing couples' satisfaction from their relationship [10].
Due to the fact that one of the most important reasons for marital conflict is lack of proper communication skills and also considering that TA is approach in which its training would recognize ego states of the self and the partner, establish a healthy relationship devoid of psychological games and increase intimacy, aiding couples to form a more effective, more compatible relationship with one another.

On the one hand, the research demonstrated that TA training enhances overall performance of family and its areas in couples [11], their intimacy and consensus over different subjects [12]. It also increases satisfaction, positive feelings and marital skills [13], quality of life [14], improves couples' love making methods [15] and raises people's social adjustment [16]. On the other hand, this approach reduces marital frustration [14], couples' conflicts [12] as well as marital instability and depression and anxiety in couples experiencing emotional divorce [13]. Danesh [17] and Zahrakar [18] in Tehran and Torkan, Kalantari, and Molavi [19] in Esfahan found that TA is effective in increasing marital adjustment. However, there are other studies which the results of them aren't consistent with the results of these researches and do not confirm effectiveness of TA group therapy on marital adjustment $[20,21]$.

Due to the fact that one of the most important reasons for marital conflict is lack of proper communication skills and also considering that TA is approach in which its training would recognize ego states of the self and the partner, establish a healthy relationship devoid of psychological games and increase intimacy, aiding couples to form a more effective, more compatible relationship with one another. Furthermore, there are conflicting findings regarding the effectiveness of this approach on marital adjustment which confirm need for this research. However several investigations have studied effectiveness of TA group therapy on marital adjustment in Iran that their results are antithesis. Meanwhile, similar research of this study has not been achieved in outside of Iran which examines exactly effectiveness of TA on marital adjustment. So this research has tried 
to increase the hours of sessions (total 24 hours) and appropriate treatment strategies in TA seeks to answer this question whether "TA really can increase marital adjustment by using training on strokes, couples' affectional expression, recognition of ego states and conclusion of growth contract and increasing marital cohesion and satisfaction - which are components of marital adjustment - by activating couples' adult ego state?"

\section{Method}

This is quasi-experimental study with control group, pretest-posttest design and 3 months follow-up test.

The statistical population consisted of all the couples who were referred at One Counseling Center in Mashhad during March 21, 2013 to September 22, 2013.

In order to implement the project, initially invoke was announced for couples who seeking to participate in the group therapy. Study inclusion criteria which include minimum marriage length of one year, minimum education of high school diploma, and the age range of 20-40 years old. Due to limitations of researcher, those who agreed to participate and had included criteria were 16 couples and they were selected by convenience sampling method and were assigned into control and experiment groups randomly. At first, each of experiment and control groups consisted of 8 couples. Once the pretest was performed during the first week, a couple of experimental group was excluded because of the unwillingness to participate in session of group. Moreover, one of the couples in the control group deterred to complete questionnaires at posttest and followup stages. A total, each experimental and control groups, consisting of seven couples (7 women and 7 men) participated in this study. One out of eight couples, i.e. 12.5 percent of the data were excluded due to lack of cooperation. Initially invoke was announced for couples who seeking to participate in the group therapy. Then, pretest was performed on qualified applicant couples. The couples completed the Dyadic Adjustment Scale individually. After taking pretest and determination of all members of the experimental and control group, matching of the group members was done based on agreements and scheduling of meetings. The group therapy sessions for the experiment group were held once week at one counseling center in Mashhad. Instruction of the sessions was carried out in 8 sessions of 3 hours according to the therapeutic methods introduced in the book "TA Today - A New Introduction to TA" by Stewart and Jones [27].

In the first session, research's goals and the rules of the group were explained to participants and the TA theory was introduced to them. Afterward, the researcher introduced the strokes, their types and ways to obtain it. In each session, the relevant notes and assignments were offered. In the second session, the couples became familiar with their inner parent, adult, and child as well as their elements. In the third session, reciprocal (complementary) and crossed transactions were instructed and after that the couples learned about the first and second rule of forming relationships. In the fourth session, the couples were taught about ulterior transactions and the third rule of forming relationships. The fifth session was earmarked on introducing psychological games and members reviewed several marital psychological games. The Karpman drama triangle and Berne's Formula $G$ were instructed. During the session, the couples learned about the games, they were involved in using the game plan search process. At the end of the session, couples' games were interpreted. In the sixth session, the couples learned the different ways of how to deal with games as well as how to put an end to their own games. In the seventh session, the couples became familiar with various circumstances in life and they discussed the topic and exchanged viewpoints. In the last session, the material offered during the previous sessions was reviewed.

Entire this process lasted for 8 weeks that after the 8 weeks (in the last session), posttest was performed. Then after three months without any intervention and experimental group was invited to perform test.

Control group as well as experimental group 
completed the questionnaire in three steps. The first stage was conducted at the beginning of the plan concurrently with the experiment group. The second stage was performed after 8 weeks without any intervention and simultaneously with the experiment group. At the third stage, after three months from the end of the meetings with the experimental group were invited in clinics and completed questionnaires. To collect data, Dyadic Adjustment Scale (DAS) were used. 32-item Dyadic Adjustment Scale (DAS): This scale was developed by Spanier [6] to measure dyadic (husband and wife, etc.) adjustment and is self-evaluation questionnaire. This scale which was used widely in studies relating to marital satisfaction is 32-item tool [22] that comprises four subscales, namely dyadic satisfaction, dyadic cohesion, dyadic consensus, and affectional expression [6]. This scale eventually gives 5 scores that include the scores of each 4 subscales as well as a total score, in the range 0 to 151 , for all questions. Higher scores indicate higher marital adjustment [23]. People with scores of 101 or below are considered by Spanier to be incompatible. In his research, the total mean score of this scale was 114.8 for the married people and 70.7 for the divorcees [24]. Up to 1984, this scale has been used in one thousand studies as the main research tool [22] and general indices of marital frustration may be determined using this scale. The studies pertaining to the reliability and validity of this scale have always been positive and Spanier reported the internal consistency coefficient of 0.92 to 0.96 as well as high criterion validity for this widely used scale [25]. Quality of marital life from the standpoint of husband and wife (or any two individuals living together) and the general indices of marital frustration can be determined by using this scale .

Spanier determined the reliability of the subscales of dyadic satisfaction, dyadic consensus, dyadic cohesion and affectional expression in dyadic relationships as 0.94, $0.90,0.86$, and 0.73 respectively. This data indicates that the components of total scale had sufficient reliability that approved their application. In interval of more than 11 weeks, the test-retest reliability of the equivalent scale is reported to be $\mathrm{r}=0.96$ that suggests consistency of the structure. The questionnaires were filled out in the researcher presence. None of the information will be released individually and the respondents were anonymous and all the information was kept confidential in this study. The participants were free to leave the study at any time.

Central indices of descriptive statistics, multi-factor variance analysis with repeated measurements with SPSS-19 were used to analyze the data.

\section{Results}

The statistical population consisted of 28 participants (14 couples). In the experiment group, 11 participants had bachelor's degrees and lower and 3 participants had degrees higher than the bachelor's degree. In the control group, 12 participants had bachelor's degrees and lower and 2 participants had degrees higher than the bachelor's degree. In total, 12 women and 11 men had bachelor's degrees and lower and 3 men and 2 women had degrees higher than the bachelor's degree. The demographic characteristics of sample can be seen in Table 1.

Table1 Frequency of groups according to educational level and gender

\begin{tabular}{lcccc}
\hline \multirow{2}{*}{ Educational level } & Gender & \multicolumn{2}{c}{ Groups } & \multirow{2}{*}{ Total } \\
\cline { 3 - 4 } & & Experimental & Control & \\
\hline Bachelor and & Female & 6 & 6 & 12 \\
lower & Male & 5 & 6 & 11 \\
\hline \multirow{2}{*}{ Higher than } & Female & 1 & 1 & 2 \\
Bachelor & Male & 2 & 1 & 3 \\
& Total & 14 & 14 & 28 \\
\hline
\end{tabular}


Each person has five scores in this research, at all three stages of pretest, posttest, and followup. The mean and standard deviation of five components in the two experiment and control groups at pretest, posttest, and follow-up stages may be found in Table 2 .

The mean of marital adjustment components in the experiment group at pretest and posttest stages, has increased. In view of Table 2 , This increase in value in posttest compared to pretest for overall adjustment, dyadic satisfaction, dyadic cohesion, dyadic consensus, and affectional expression was respectively 7,6 , 4, 5, and 17 percent (Table 2).

Table2 Descriptive indexes dyadic adjustment scale in pretest, posttest and follow up stages in experimental and control group

\begin{tabular}{|c|c|c|c|c|}
\hline \multirow[b]{2}{*}{ Groups } & Component & Pretest & Posttest & Follow-up \\
\hline & & $\begin{array}{c}\text { Standard } \pm \text { Mean } \\
\text { deviation }\end{array}$ & $\begin{array}{c}\text { Standard } \pm \text { Mean } \\
\text { deviation }\end{array}$ & $\begin{array}{c}\text { Standard } \pm \text { Mean } \\
\text { deviation }\end{array}$ \\
\hline \multirow{5}{*}{ Experimental } & Total Adjustment & $92.9 \pm 4.2$ & $99.3 \pm 8.3$ & $98.6 \pm 8$ \\
\hline & Dyadic Satisfaction & $30.6 \pm 3.5$ & $32.4 \pm 3.9$ & $32 \pm 3.9$ \\
\hline & Dyadic Cohesion & $16.9 \pm 1.8$ & $17.6 \pm 2.1$ & $17.6 \pm 2.2$ \\
\hline & Dyadic Consensus & $38.8 \pm 4.5$ & $40.9 \pm 6.8$ & $39.9 \pm 6.9$ \\
\hline & $\begin{array}{l}\text { Affectional } \\
\text { Expression }\end{array}$ & $7.3 \pm 1.1$ & $8.6 \pm 0.1$ & $8.9 \pm 1.2$ \\
\hline \multirow{5}{*}{ Control } & Dyadic Satisfaction & $91.1 \pm 7$ & $90.1 \pm 6.2$ & $88.8 \pm 7$ \\
\hline & Dyadic Satisfaction & $30.1 \pm 3.2$ & $30 \pm 3.4$ & $29.2 \pm 3.6$ \\
\hline & Dyadic Cohesion & $15.6 \pm 1.5$ & $15.6 \pm 1.1$ & $15.6 \pm 15.6$ \\
\hline & Dyadic Consensus & $37.7 \pm 3.2$ & $37.1 \pm 3.4$ & $36.2 \pm 3.4$ \\
\hline & $\begin{array}{l}\text { Affectional } \\
\text { Expression }\end{array}$ & $7.35 \pm 1.7$ & $7.4 \pm 1.4$ & $7.3 \pm 1.3$ \\
\hline
\end{tabular}

According to Table 2, the mean of overall marital adjustment, dyadic satisfaction, dyadic cohesion, dyadic consensus, and affectional expression between the couples in the experiment group has increased respectively 6 , $4,4,2$, and 21 percent in the follow-up stage compared to the pretest stage.

At first, multi-variable tests were used to investigate the significance of the difference of marital adjustment in the experiment and control groups at pretest, posttest, and followup stages. The results pertaining to Hotelling's T statistic for intergroup effects and the interaction of marital adjustment components indicated significant interaction between the scores of overall marital adjustment $(\mathrm{F}(2,25)=7.35$, $\mathrm{p}=0.003)$ and couples' affectional expression $(F(2,25)=8.07, p=0.002)$ at three measurement stages of pretest, posttest, and follow-up in two experiment and control groups.

Multi-factor variance analysis with repeated measurements were used to investigate the significance of the marital adjustment differences of the experiment and control groups at pretest, posttest, and follow-up stages. The results may be found in Table 3 .

According to analysis of variance within groups with repeated measurement, there is significant difference between marital adjustment scores $(\mathrm{F}=13.44, \mathrm{p}=0.001)$ and couples' affectional expression $(\mathrm{F}=9.44, \mathrm{p}=0.001)$ at pretest, posttest, and follow-up stages (Table 3 ).

Table 3 Test of within groups effects of variance analysis with frequent measurement of total adjustment and affectional expression scores of control and experimental groups

\begin{tabular}{lccccc}
\hline Source of changes & Sum of square & Degrees of freedom & Mean of square & F & Significant value \\
\hline Total Adjustment & 281.16 & 1.24 & 225.55 & 13.44 & 0.001 \\
$\begin{array}{l}\text { Error } \\
\text { (factor) }\end{array}$ & 543.76 & 32.41 & 16.77 & & \\
$\begin{array}{l}\text { Affectional expression } \\
\begin{array}{l}\text { Error } \\
\text { (factor) }\end{array}\end{array}$ & 9.44 & 1 & 9.44 & 6.28 & 0.001 \\
\hline
\end{tabular}


The results concerning paired comparisons indicated that there is significant difference between the experiment $(\mathrm{M}=96.97)$ and control $(M=90.02)$ groups in terms of marital adjustment as well as between the experiment $(\mathrm{M}=8.28)$ and control $(\mathrm{M}=7.35)$ groups in terms of affectional expression ( $\mathrm{I}-\mathrm{J}=6.95, \mathrm{p}=0.001$ ). Table 4 demonstrates results pertaining to paired comparisons of pretest, posttest, and follow-up stages.

Due to Table 4 suggests that there is significant difference in overall marital adjustment between pretest and posttest scores $(\mathrm{p}=2.67)$ as well as between follow-up and posttest scores $(p=0.96)$. This implies that TA group therapy has increased marital adjustment; however, but this score has decreased over time.

Table 4 Paired comparison of total adjustment and affectional expression scores means at three pretest, posttest, and follow-up stages

\begin{tabular}{lccccc}
\hline Component & Measurement stages & Mean & Pretest & Posttest & Follow up \\
\hline \multirow{2}{*}{ Total Adjustment } & Pretest & 92.03 & - & -2.67 & -1.71 \\
& Posttest & 94.71 & 2.67 & - & 0.96 \\
& Follow-up & 93.75 & 1.71 & -0.96 & - \\
& Pretest & 7.35 & - & -0.64 & -0.75 \\
Affectional & Posttest & 8 & 0.64 & - & -0.10 \\
Expression & Follow-up & 8.10 & 0.75 & 0.10 & - \\
& & & & & \\
\hline
\end{tabular}

In addition, there is significant difference in affectional expression scores between pretest and posttest scores $(\mathrm{p}=0.64)$ as well as between pretest and follow-up scores $(p=0.75)$. This analysis indicates that affectional expression between couples after the intervention has increased and this increase has been maintained over time.

\section{Discussion}

The present research which aims to provide a practical method for psychotherapists and counselors investigates the effectiveness of TA group therapy on increasing marital adjustment. By this aim present research may be considered by two following questions: Does TA group therapy generally affect marital adjustment? Whether TA training can increase solidarity, harmony and affection between couples?

The findings showed that TA group therapy increases couples' overall marital adjustment and the couples will preserve this change over time. This finding was consistent with previous research about effectiveness of TA psychotherapy in overall adjustment. In consistent with this finding, Slavik, Carlson, and Sperry [28] as well as Torkan et al. [19] demonstrated that the TA approach leads to increase marital adjustment of couples.

Also there are studies that disagree with this finding including the research titled "Investigating Effectiveness of TA Group Therapy on Increasing Emotional Intelligence and Marital Adjustment." This research suggested that this type of therapy considerably affected emotional intelligence; however, changes in the samples' marital satisfaction were not significant [20]. Also, Kafi et al. in research which entitled as "The Effectiveness of TA Group Therapy in Marital Adjustment and Prevention of Relapse of Detoxified People," [21] showed that there was significant difference between the two groups in terms of temptation toward drug abuse but no significant difference was observed between marital adjustment and the probability of drug abuse.

In two latter mentioned studies, effectiveness of TA group therapy in marital adjustment along with other variables such as emotional intelligence or prevention of relapse of detoxified people has been investigated. It seems that considering other components such as emotional intelligence, etc. has been caused focusing on relationships and marital 
adjustment in sessions and this is reason for lack of significant of effectiveness

In explaining the increase of overall marital adjustment by TA can be said that according to this approach freedom of "adult" with which "parent" review the text to accept or reject today is basic condition for successful marriage. Furthermore, the status of "child" is examined by the "adult" in order to identify retaliation signs and to see whether or not the child has rebelled or resorted games to escape the feeling of "not being OK" [10]. For this reason, couples learn in therapy sessions that their "adult" needs to supervise their inner "child" and "parent" for a better, more compatible relationship should use ego state in any circumstances. They learn to use their stroking parent more instead of the scolding parent in their relationship. During the therapy process, the couples are guided to resolve any elimination or contamination in their ego state, thus using all three ego states in a balanced, healthy manner in relationships with one another. All these interventions can help reduce couples' conflicts consequently increased their adjustment.

Another finding of this research showed that TA group therapy has not affected dyadic satisfaction and the experimental group showed no signs of change in this component compared to the control group after the TA group therapy. This finding disagrees with that of research of Torkan et al. [19]. In their research, Torkan et al. investigated effectiveness of TA group therapy on increasing dyadic satisfaction. The results of present research also disagree with research of Salamat [12], where TA group therapy was utilized for reducing marital conflicts which as result marital conflicts decreased and couples' satisfaction increased. However, according to previous studies that have demonstrated this effectiveness and according to mean of the experimental group compared to the control group increased but this increase was not statistically significant and we cannot ignore the effectiveness of TA marital satisfaction. The low number of treatment sessions could be the reason for the issue.
Another finding of this study was that TA group therapy fails to increase dyadic cohesion and dyadic consensus. This finding is consistent with research of Salamat [12]. Salamat demonstrated that instructing of TA communication skills has not affected marital consensus regarding religious matters. He also showed that instructing of TA communication skills has not increased couples' consensus with respect to socializing with friends and relatives. Since marital consensus in the Dyadic Adjustment Scale is measured in very diverse and different fields such as expending the income and the financial affairs of the family, leisure and recreation, religious matters, affectional expression, friends, sexual relationship, the time spent together, etc., TA group therapy has been unable to increase marital consensus in all fields during the short period of only in short time of 8 sessions. However it may be said that cohesion may be somewhat increased if longer time is spent on the "adult"-"adult" relationship and contracts are made regarding all types of couples' conflicts, consensus.

Data analysis showed TA group therapy affects affectional expression in couples and this effect is maintained over time. Perhaps the instruction of communication skills has caused the couples to be able to find the "child" ego state in one another (under the supervision of the adult ego state) and stroke it and thus become more intimate with each other.

If positive strokes in marital relationship are insufficient for satisfying the needs for stroking, the husband and wife immediately move toward negative strokes because people believe that any kind of stroke is better than no stroke at all [27]. In such conditions, TA lessons suggest the couples do something so that they receive positive, joyful strokes instead of negative, painful ones. After getting familiar with different types of strokes, the couples exchange unconditional, positive strokes more than before. They also use same level of conditional strokes when they intend to criticize their spouse in a manner that they merely criticize the spouse's behavior 
and not their entire personality. During the therapy process, they understand that more they stroke each other, the more they receive strokes. Becoming familiar with stroke filters, they attempt to put them aside and receive more strokes. All these lessons can be reasons for increased affectional expression in couples.

TA help people to understand their ego states as well as their spouses and lead to better communication. Couples by recognizing their ego states and reinforcing the "adult" at any time consciously choose to behave using any of the ego states. They learn to replace crossed and ulterior transactions with reciprocal transactions in order to reduce conflicts. It may generally be stated that the therapy process is method which leads couples toward healthy transactions. "A healthy transaction is relationship where the message and response are exchanged in the form of a parallel, direct, dynamic, and positive transaction without any hidden, indirect, static, and negative relationship" [28].

The couples were guided during session of therapy identify the psychological games between themselves and their spouse, thereby leaving their default roles of "persecutor," "rescuer," and "victim." Psychological games are certain method to gain a backlog of strokes. For this reason, couples help to improve their relationship and prevent entrance to psychological games by abandoning games and using the positive, healthy strokes needed of their spouse. The teachings of TA ask couples to have intimacy with each other and communication where genuine feelings and desires have exchanged without any hidden messages. Intimacy is choice for the child-child relationship which is founded by their adults, so that in manner that both sides understand commitments and pacts between themselves and are responsible toward each other [10].

Limitations of this research included; lack of a randomized selection of participants, couples' low initial motivation (small sample volume) to participate in group therapy and the existence of uncontrolled variables such as social class and their interference on results that caused problems for the data's generalization.

\section{Conclusion}

It seems that the TA method and its lessons in this research have helped couples get to know each other, be equipped with effective communication and problem solving skills, decontaminate adult and improve its performance, establish reciprocal transactions, get rid of previous ineffective, destructive patterns and, as a result, abandon psychological games, improve couples' relationship, and increase their intimacy and adjustment. This approach may thus be employed in curing numerous marital maladjustments and conflicts. In addition, holding workshops where TA is taught to young couples encourage them to have better knowledge and mastery over their relationship, preventing clashes and conflicts between them.

\section{Acknowledgments}

The authors wish to express their gratitude to all participants.

\section{Contribution}

Study Design: SS, BGH

Data Collection and Analysis: SS, SMH, MH

Manuscript preparation: SS, AMA

\section{Conflict of Interest}

"The authors declare that they have no competing interests."

\section{Funding}

The authors received no financial support for the research, authorship and/or publication of this article.

\section{References}

1- Lebow JL, Chambers AL, Christensen A, Johnson MS. Research on the treatment of couple distress. $J$ Marital Fam Ther2012; 38(1): 145-68.

2- Khalilzade Matori M, Honarparvaran N, Refahi Z. The effectiveness of integrative approach of Bowen and object relations theories on marital adjustment and sexual satisfaction of women. Reef Resources Assessment and Management Technical Paper2014; 40(2): 255-61.

3- Thompson JM, Wiffen EV, Blain MD. Depressive symptoms, sex, and perceptions of intimate relationships. J Soc Pers Relat1995;12: 49-66. 
4- AlL- Krenawi A. A study of psychological symptoms, family function, marital and life satisfactions of polygamous and monogamous women: The Palestinian case. Int J Soc Psychiatry2012;1958(14): 38479-86.

5- Sinha SP, Mukerjee N. Marital adjustment and personal space orientation. J Soc Psychol1990; 130(5): 633-9.

6- Spanier GB. Measuring dyadic adjustment: new scales for assessing the quality of marriage and similar dyads. J Marriage Fam Couns 1976; 38(1): 15-28.

7- Alayi Z, Ahmadi Gatab T, Babaei Zad Khamanen A. Relation between communication skill $\mathrm{s}$ and maritaladaptability among university students. Procedia Soc Behav Sci2011; 30: 1369-75.

8- Vinella P. Transactional analysis counseling groups: theory, practice, and how they differ from other TA groups. Transactional Analysis Journal2013;43(1): 68-79 9- Clarkson P. Transactional analysis psychotherapy: an integrated approach. London, UK: Routledge; 2013.

10- Harris T. I'm OK, You're OK. Manhattan, New York, US: Harper; 2004.

11- Sodani M, Mehrabizade M, Soltani Z. The effectiveness of group training in Transactional Analysis on performance of incompatible couples. Journal of Family Counseling \& Psychotherapy2012; 2(3): 267-87. 12- Salamat M, Zamani A, Alahyari T. The effect of teaching communication skills on marital conflict by transactional analysis. Journal of Applied Psychology2007; 1(3): 29-42.

13- Akbari A, Poursharifi H, Azimi Z, Fahimi S. The effectiveness of transactional analysis group therapy on satisfaction, adjustment, positive feelings and intimacy in couples with emotional divorce experience. Journal of Family Counseling \& Psychotherapy2012; 2(4): 455-84.

14- Sodani M, Dehghani M, Dehghanzadeh Z. The efficacy of group training in transactional analysis on couples burnout and quality of life. Journal of Family Counseling \& Psychotherapy2012; 3(2):159-80.

15- Sadeghi M, Ahmadi SA, Bahrami F, Etemadi O, Pour Seyed SR. The effect of Transactional analysis training on love styles of couples. Researches of Cognitive and Behavioral Science2013; 3(2): 71-84.

16- Emam Jomeh Zadeha M, Gorji Y, Javadzadeh A. A social work study on effectiveness of transactional analysis training on social adjustment: a case study of women with spouses with drug addiction. Growing Science $2013 ; 3,431-4$.
17- Danesh E. The impact of transactional analysis method on increasing marital compatibility of incompatible couples. Journal of Family Research2010;6(3): 373-91.

18- Zahrakar K. A study of the effectiveness of transactional analysis with marital group therapymethod on enhancement of martial adjustment among married students at Islamic Azad UniversityIslamshar branch. Journal of Counseling Research \& Developments2012; 11(42): 29.

19- Torkan H, Kalantari M, Molavi H. The efficacy of transactional analysis group therapy on marital satisfaction. Journal of Family Research2006; 2(8): 383-403.

20- Salari M, Amin Yazdi S, Ghanbari Hashem Abad B. The efficacy of transactional analysis group therapy on increasing emotional intelligence and marital adjustment. The third national congress on family pathology .Tehran: Family research institute of Shahid Beheshti University; 2008. pp:215.

21- Kafi SM, Mollazadeh Esfanjani R, Noori M, Salehi EI. The effectiveness of transactional behavior analytic group therapy on the marital adjustment and prevention of re lapse in detoxified people. Journal of Psychology2011; 6(23): 116-38.

22- Busby DM, Christensen C, Crane DR, Larson $\mathrm{JH}$. A revision of the dyadic adjustment scale for use with distressed and no distressed couples: construct hierarchy and multidimensional scales. J Marital Fam Ther 1995; 21(3): 289-308.

23- Hamamci Z. Dysfunctional relationship beliefs in marital satisfaction and adjustment. J Soc Behav Pers2005; 33: 313-28.

24- Sanayi B, Barati T. Comparison of family and marriage. Tehran: Besat press; 2000.

25- Danesh E. The role of self-analysis in couples' dispute resolution. Karaj: Golshan press; 2005.

26- Orourke N, Cappeliez P. Intra-couple variability in marital aggrandizement: idealization and satisfaction within enduring relationships. Current Research in Social Psychology2003; 8(15): 206-25 .

27- Stewart I, Joins V. TA Today, a new introduction to Transactional Analysis. 15th ed. Tehran: Dayereh press; 2011.

28- Slavik S, Carlson H, Sperry L. Adlerian marital therapy with the passive aggressive partner. Am J Fam Ther2007; 20: 25-35.

Copyright(C) 2016 ASP Ins. This open-access article is published under the terms of the Creative Commons Attribution-NonCommercial 4.0 International License which permits Share (copy and redistribute the material in any medium or format) and Adapt (remix, transform, and build upon the material) under the Attribution-NonCommercial terms. 